\title{
Update on the Evaluation of Thyroid Nodules
}

\author{
Victor J. Bernet and Ana-Maria Chindris \\ Division of Endocrinology, Department of Medicine, Mayo Clinic in Florida, Jacksonville, Florida
}

\begin{abstract}
Thyroid nodules (TN) are prevalent in the general population and represent a common complaint in clinical practice. Most are asymptomatic and are associated with a $7 \%-15 \%$ risk of malignancy (1). Methods: PubMed and Medline were searched for articles with a focus on the epidemiology, diagnosis, and management of TN over the past $5 \mathrm{y}$. Results: The increase in frequency of imaging has led to a rise in the incidence of incidentally diagnosed TN. The initial evaluation of a TN includes assessing thyroid function, clinical risk factors, and neck imaging. Ultrasound remains the gold standard for assessing TN morphology, and biopsy is the standard method for determining whether a TN is benign. Recently published risk stratification systems using morphologic characteristics on ultrasonography have been effective in reducing the number of unnecessary biopsies. Advances in molecular testing have reduced the number of surgical procedures performed for diagnostic purposes on asymptomatic TN with indeterminate cytology. Scintigraphy is the first-line study for assessing a hyperfunctioning nodule. Many TN can be followed clinically or with serial ultrasound after the initial diagnosis. Surgical intervention is warranted when local symptoms are present, in patients with clinical risk factors, as well as in most situations with malignant cytology. Active surveillance is an option in cases of micropapillary thyroid cancer. Emerging nonsurgical approaches for treating TN include ethanol ablation for TN; sclerotherapy for thyroid cysts; and thermal techniques, such as radiofrequency ablation, laser ablation, microwaves, and high-intensity focused ultrasound. Conclusion: Most TN are benign and can be safely monitored. The indications for biopsy and frequency of imaging should be tailored on the basis of risk stratification. Treatment options should be individualized for each patient's particular situation. Active surveillance should be considered in certain cases of papillary microcarcinoma.
\end{abstract}

Key Words: oncology; fine-needle aspiration; imaging; molecular testing; risk stratification; thyroid nodules

J Nucl Med 2021; 62:13S-19S

DOI: 10.2967/jnumed.120.246025

\section{$\mathbf{T}$} hyroid nodules (TN) are commonly encountered in clinical practice, with a prevalence ranging between $20 \%$ and $60 \%$ in prospective, randomly selected patients (1-3). Although some may cause local symptoms and are diagnosed through clinical examination, at present most are reported as incidental findings during unrelated imaging (4-7). Although the incidence of thyroid cancer has increased in recent decades, most $\mathrm{TN}$ are benign, with a rate of malignancy of less than $5 \%(8,9)$.

A newly diagnosed TN should be evaluated to ascertain whether it is benign or malignant and, for symptomatic benign $\mathrm{TN}$, to

Received Jul. 6, 2020; revision accepted Sep. 29, 2020.

For correspondence or reprints, contact Victor J. Bernet (bernet.victor@ mayo.edu).

COPYRIGHT (C) 2021 by the Society of Nuclear Medicine and Molecular Imaging. establish the indications for intervention to alleviate associated local symptoms. Although routine population screening for TN is not recommended, particular attention should be given to situations in which risk factors for thyroid cancer are present, including childhood history of exposure to ionizing radiation, variations in dietary iodine intake, inherited genetic syndromes associated with thyroid cancer (familial adenomatous polyposis, Carney complex, Cowden syndrome, PTEN hamartoma tumor syndrome, and Peutz-Jeghers syndrome), or a family history of medullary thyroid cancer or multiple endocrine neoplasia syndrome (10). The purpose of this article is to review and summarize recent trends in the diagnosis and management of incidentally discovered TN.

\section{METHODS}

We performed a PubMed and Medline search to identify articles focused on the epidemiology, diagnosis, and management of TN over the past $5 \mathrm{y}$. We reviewed 135 articles, including their reference lists, for additional pertinent articles.

\section{RESULTS AND DISCUSSION}

\section{Imaging}

Thyroid Ultrasound (US). Thyroid US is the gold standard for assessing TN morphology and is generally recommended for nodules diagnosed either clinically or through other imaging modalities. Because of significant improvements in the performance of US technology, it is now possible to provide a detailed morphologic description of thyroid anatomy. Several ultrasonography features of $\mathrm{TN}$, such as size, echogenicity, nodule border, vascular pattern, nodule shape, tissue stiffness (as assessed by elastography), presence of micro- or macrocalcifications, and cervical lymph nodes with an abnormal appearance, are all characteristics that have been associated with a risk of thyroid cancer (Fig. 1]). However, individual US features are limited by a broad range of sensitivity and specificity for malignancy; therefore, none can be considered alone to be accurate for diagnosing thyroid cancer (11). As a result, risk assessment strategies were developed to determine the risk of malignancy that would justify additional assessment and intervention. At present, there are several such protocols.

In 2017, the American College of Radiology issued a standardized risk stratification system, the Thyroid Imaging, Reporting and Data System (TI-RADS), which is based on a point scoring system that takes into account TN composition, echogenicity, shape, size, margins, and presence of echogenic foci (12). The recommendation for fine-needle aspiration (FNA) biopsy (FNAB) is based on a combination of the TI-RADS score and nodule size. The American Thyroid Association system is based more on sonographic pattern recognition and classification of nodule appearance into 5 categories with associated ranges of cancer risk: benign $(<1 \%)$, very 


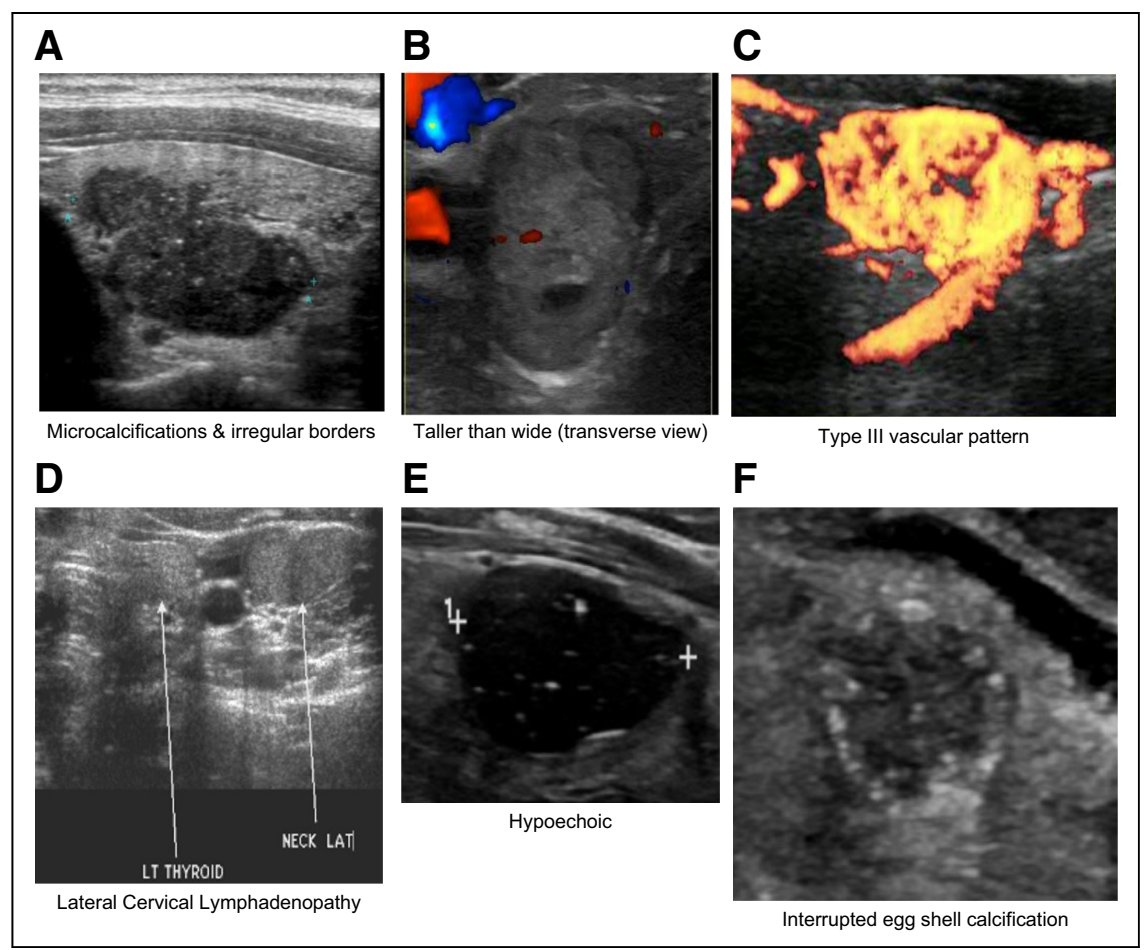

FIGURE 1. US characteristics associated with risk of thyroid cancer. (A) Hypoechoic TN with irregular, lobulated borders and interspersed microcalcifications. (B) Nodule that is more tall than wide on transverse US view. (C) Nodule with prominent vascularity throughout (type III vascular pattern). (D) Left (LT) lateral cervical lymphadenopathy in patient with $1.9-\mathrm{cm}$ isthmus nodule. Both nodule and lymph nodes were proven to contain papillary thyroid cancer. (E) Densely hypoechoic nodule. (F) Interrupted (or fenestrated) eggshell calcification pattern in nodule with papillary thyroid cancer.

low $(<3 \%)$, low $(5 \%-10 \%)$, intermediate $(10 \%-20 \%)$, and high $(>70 \%-90 \%)$ (1). A combination of nodule size and appearance is used to recommend when FNAB should be considered, similar to TI-RADS. Of note, both systems recommend against automatic FNAB sampling of nodules smaller than $1 \mathrm{~cm}$ and lean toward active surveillance with close follow-up for these small, suspicious nodules $(1,13,14)$. Similar scoring systems have been issued by the Korean Society of Thyroid Radiology (15), European Thyroid Association (16), and American Association of Clinical Endocrinologists (17). A summary of these scoring systems is shown in Table 1.

CT and MRI. CT and MRI have limited roles in the evaluation of TN and are generally indicated in patients with a clinical suggestion of advanced thyroid malignancy, for presurgery planning, for the assessment of central- and lateral-compartment cervical lymph nodes, and for the evaluation for airway, digestive, or vascular anatomy involvement when indicated (1).

${ }^{18} \mathrm{~F}-\mathrm{FD} G \mathrm{PET} / \mathrm{CT}$. Incidental TN have a prevalence of $1 \%-2 \%$ of all ${ }^{18} \mathrm{~F}$-FDG PET/CT scans (18). The reported rate of cytologyproven malignancy ranges between $24 \%$ (19) and $58.2 \%(20)$, whereas diffuse uptake is associated with a much lower malignancy rate- $4.4 \%(21)$. A metaanalysis of 18 studies $(n=55,160)$ found that $1 \%$ of cases had thyroid incidentalomas diagnosed on ${ }^{18}$ F-FDG PET, with a $33.2 \%$ incidence of malignancy and papillary thyroid cancer representing $82.2 \%$ of these cases (22). Despite this increased incidence, newly diagnosed incidental thyroid cancers do not appear to affect mortality. In a retrospective review of 45,000 PET/CT scans, the incidence of thyroid cancer in thyroid incidentalomas was $36 \%$; over a $24-$ mo median follow-up, most deaths (181) were related to the primary malignancy and not thyroid cancer (23).

Scintigraphic Imaging for TN. A newly diagnosed TN with a subnormal thyroidstimulating hormone (TSH) level should next be evaluated with a radioactive iodine uptake and thyroid scan to determine whether it is hyperfunctioning (1). In such cases, US can be considered to assess for coexistent nonfunctioning nodules, which may require additional evaluation. Of note, small hyperfunctioning TN may not cause full TSH suppression; therefore, if clinically indicated, scintigraphy should be considered for TSH levels at the lower end of normal.

Before the prevalence of US, scintigraphy-based thyroid imaging with ${ }^{99 \mathrm{~m}} \mathrm{Tc}$-pertechnetate $\left(\mathrm{TcO}_{4}{ }^{-}\right)$and radioactive iodine $\left({ }^{131} \mathrm{I}\right.$ and $\left.{ }^{123} \mathrm{I}\right)$ played a significant role in the evaluation of $\mathrm{TN}$ and multinodular goiters (24). In the United States, nuclear thyroid imaging for the evaluation of thyroid nodularity is primarily reserved for cases in which TSH suppression is evident and the associated presence of thyrotoxicosis is suspected (25). Thyroid scintigraphy appears to be more commonly used in other parts of the world, including Europe (26). Although "cold" nodules on scintigraphy can represent a malignancy, many benign $\mathrm{TN}$ will also appear to be hypofunctioning. In contradistinction, "hot" hyperfunctioning nodules are rarely malignant (Fig. 2) (27).

A review of 6 articles in 1981 revealed the following thyroid cancer rates associated with the respective scintigraphy findings: hypofunctioning nodules, $16 \%$; normofunctioning nodules, $-9 \%$; and hyperfunctioning nodules, $-4 \%$ (28). A discrepancy between the uptake of ${ }^{99 \mathrm{~m}} \mathrm{Tc}$ and the uptake of ${ }^{131} \mathrm{I}$ by cancerous $\mathrm{TN}$ has been reported, particularly in follicular thyroid cancer. Nodule ${ }^{99 \mathrm{~m}} \mathrm{Tc}$ uptake was noted, whereas with ${ }^{131} \mathrm{I}$ imaging, the nodules appeared "cold" (29). Therefore, when scintigraphy is used for TN assessment, ${ }^{123} \mathrm{I}$ is preferred over ${ }^{99 \mathrm{~m}} \mathrm{Tc}$ as an imaging agent. A recent study comparing ${ }^{123}$ I scintigraphy and thyroid US for referral for FNAB found concordant recommendations in $79.4 \%$ of cases. Discordant recommendations included a US-based referral for FNAB for functional nodules $(3.8 \%)$ and a ${ }^{123}$ I-based recommendation for FNAB (7.9\%) when either there was no TN on US or the nodule did not meet US-guided FNAB criteria (30).

American Thyroid Association 2015 guidelines recommend limited use of thyroid scintigraphy, primarily for cases with suppressed TSH, as the finding of an autonomous nodule would obviate the need for FNAB of that nodule except on the rare occasions when malignancy is suspected on the basis of thyroid US appearance (1). The European Association for Nuclear Medicine and the Society for Nuclear Medicine and Molecular Imaging have published joint practice guidelines that note potential uses for thyroid scintigraphy to include the evaluation of a multinodular goiter for either a hyperfunctional "hot" TN for which FNAB is not needed, the evaluation of suspicious hypofunctional "cold" areas in a 
TABLE 1

Summary of Currently Available US-Based Risk Assessment Scoring Systems

\begin{tabular}{|c|c|c|c|c|c|}
\hline Society & Benign & Low risk & Mildly suspicious & $\begin{array}{l}\text { Moderately } \\
\text { suspicious }\end{array}$ & Highly suspicious \\
\hline \multirow[t]{3}{*}{ ACR } & TI-RADS 1 & TI-RADS 2 & TI-RADS 3 & TI-RADS 4 & TI-RADS 5 \\
\hline & No FNA (2\%) & No FNA (2\%) & $\mathrm{FNA} \geq 2.5 \mathrm{~cm}$ & $\mathrm{FNA} \geq 1.5 \mathrm{~cm}$ & $\mathrm{FNA} \geq 1.0 \mathrm{~cm}$ \\
\hline & & & $\begin{array}{l}\text { Follow } \geq 1.5 \mathrm{~cm} \\
\quad(5 \%)\end{array}$ & $\begin{array}{l}\text { Follow } \geq 1.0 \mathrm{~cm} \\
\quad(5 \%-20 \%)\end{array}$ & $\begin{array}{l}\text { Follow } \geq 0.5 \mathrm{~cm} \\
\quad(>20 \%)\end{array}$ \\
\hline ATA & No FNA $(<1 \%)$ & $\begin{array}{l}\text { Consider FNA } \geq 2 \\
\mathrm{~cm}(<3 \%)\end{array}$ & $\begin{array}{l}\text { FNA } \geq 1.5 \mathrm{~cm} \\
\quad(5 \%-10 \%)\end{array}$ & $\begin{array}{l}\text { FNA } \geq 1.0 \mathrm{~cm} \\
\quad(10 \%-20 \%)\end{array}$ & $\begin{array}{l}\text { FNA } \geq 1.0 \mathrm{~cm} \\
\quad(>70 \%-90 \%)\end{array}$ \\
\hline \multirow[t]{2}{*}{ AACE/ACE/AME (17) } & No FNA (0\%) & $\mathrm{FNA} \geq 2.0 \mathrm{~cm}(1 \%)$ & $\dagger$ & $\begin{array}{l}\text { FNA } \geq 2.0 \mathrm{~cm}+ \\
\text { other risk } \\
(5 \%-15 \%)\end{array}$ & $F N A \geq 1.0 \mathrm{~cm}$ \\
\hline & & & & & $\begin{array}{c}\text { Selective FNA > } \\
0.5 \mathrm{~cm} \\
(50 \%-90 \%)\end{array}$ \\
\hline \multirow[t]{2}{*}{ ETA } & EU-TIRADS 2 & EU-TIRADS 3 & $\dagger$ & EU-TIRADS 4 & EU-TIRADS 5 \\
\hline & No FNA (0\%) & $\begin{array}{c}\text { FNA } \geq 2 \mathrm{~cm} \\
(2 \%-4 \%)\end{array}$ & & $\begin{array}{l}\text { FNA } \geq 1.5 \mathrm{~cm} \\
\quad(6 \%-17 \%)\end{array}$ & $\begin{array}{l}\text { FNA } \geq 1.0 \mathrm{~cm} \\
\quad(26 \%-87 \%)\end{array}$ \\
\hline \multirow[t]{3}{*}{ KTA } & K-TIRADS 2 & K-TIRADS 3 & $\ddagger$ & K-TIRADS 4 & K-TIRADS 5 \\
\hline & $\begin{array}{l}\text { FNA } \geq 2 \mathrm{~cm} \\
\quad(<1 \%-3 \%)\end{array}$ & $\begin{array}{c}\text { FNA } \geq 1.5 \mathrm{~cm} \\
(3 \%-15 \%)\end{array}$ & & $\begin{array}{l}\text { FNA } \geq 1.0 \mathrm{~cm} \\
\quad(15 \%-50 \%)\end{array}$ & $\mathrm{FNA} \geq 1.0 \mathrm{~cm}$ \\
\hline & & & & & $\begin{array}{l}\text { Selective FNA > } \\
0.5 \mathrm{~cm}(>60 \%)\end{array}$ \\
\hline
\end{tabular}

${ }^{*}$ Moderately suspicious is used synonymously with intermediate.

${ }^{\dagger}$ Equivalent category does not exist in that society's rating system.

‡Other risk defined as increasing size of nodule, previous head and neck radiation exposure, family history of thyroid cancer, and previous thyroid surgery or minimally invasive ablation therapy.

$\mathrm{ACR}=$ American College of Radiology; ATA = American Thyroid Association; AACE $=$ American Association of Clinical Endocrinologists; ACE = American College of Endocrinology; AME = Associazone Medici Endocrinologi; ETA = European Thyroid Association; EU-TIRADS = ETA version of TI-RADS; KTA = Korean Thyroid Association; K-TIRADS = KTA version of TI-RADS.

Risk of malignancy for each category is given in parentheses.

multinodular goiter that represent $\mathrm{TN}$ for which FNAB sampling may be required, and potential evaluation of $\mathrm{TN}$ with indeterminate FNAB cytology to identify an autonomous functioning TN (31). TSH suppression secondary to autonomous nodules can vary on the basis of local dietary iodine intake, and autonomous nodules with low reference range TSH levels have been found in populations with lower dietary iodine intake (32). The use of scintigraphy has also been proposed to allow the early identification and close follow-up of autonomous TN that can develop into full-blown thyrotoxicosis in the future (33). In summary, although it is expected that scintigraphy is not necessary in most euthyroid patients, local factors may affect the decision to use such imaging for the evaluation of thyroid nodularity.

\section{FNA of TN}

A TN that meets morphologic criteria should be further assessed by cytology of samples obtained through biopsy. Thyroid FNAB is a straightforward outpatient procedure, performed under US guidance, typically using 27- and 25-gauge sterile needles. Local anesthesia is sometimes used, although its utility in reducing patient discomfort when fine needles are used has been challenged $(34,35)$. Complications are uncommon and include local bruising and, rarely, hematoma $(36,37)$. Studies that assessed the relationship between nodule size and FNAB accuracy yielded conflicting results. FNAB accuracy ranged from $60 \%$ to $94 \%$ for nodules smaller than $1 \mathrm{~cm}$ and $80.3 \%$ to $87.5 \%$ for those larger than $4 \mathrm{~cm}(38,39)$. Core needle biopsy is currently considered when FNAB yields nondiagnostic results or when thyroid lymphoma or anaplastic thyroid cancer is suspected $(40,41)$. The Korean Society of Thyroid Radiology recommends core needle biopsy as a first-line alternative to FNAB (42). However, core needle biopsy has been associated with a higher rate of complications, including postbiopsy hematomas, bleeding from the incision site, pain, infections, transient hemoptysis, and nerve injuries $(43,44)$. According to the Bethesda criteria for reporting cytology findings, TN are classified in 6 categories, summarized in Supplemental Table 1 (supplemental materials are available at http:// jnm.snmjournals.org) along with the associated malignancy risk and management recommendations. Bethesda categories III and IV include nodules with indeterminate cytology and associated malignancy risks of $10 \%-30 \%$ and $25 \%-40 \%$, respectively (45). Historically, in these cases, a definitive diagnosis was achieved by surgical removal, leading to a significant number of unnecessary surgeries (46). More recently, the introduction of molecular testing of cytology samples has greatly reduced the need for surgical intervention. These tests are meant to identify genomic alterations associated with thyroid malignancy, such as gene mutations, fusions, and differences in RNA and microRNA expression, which are associated with a risk for malignancy (47).

The most prevalent commercially available molecular tests for TN malignancy assessment are summarized in Supplemental Table 2 


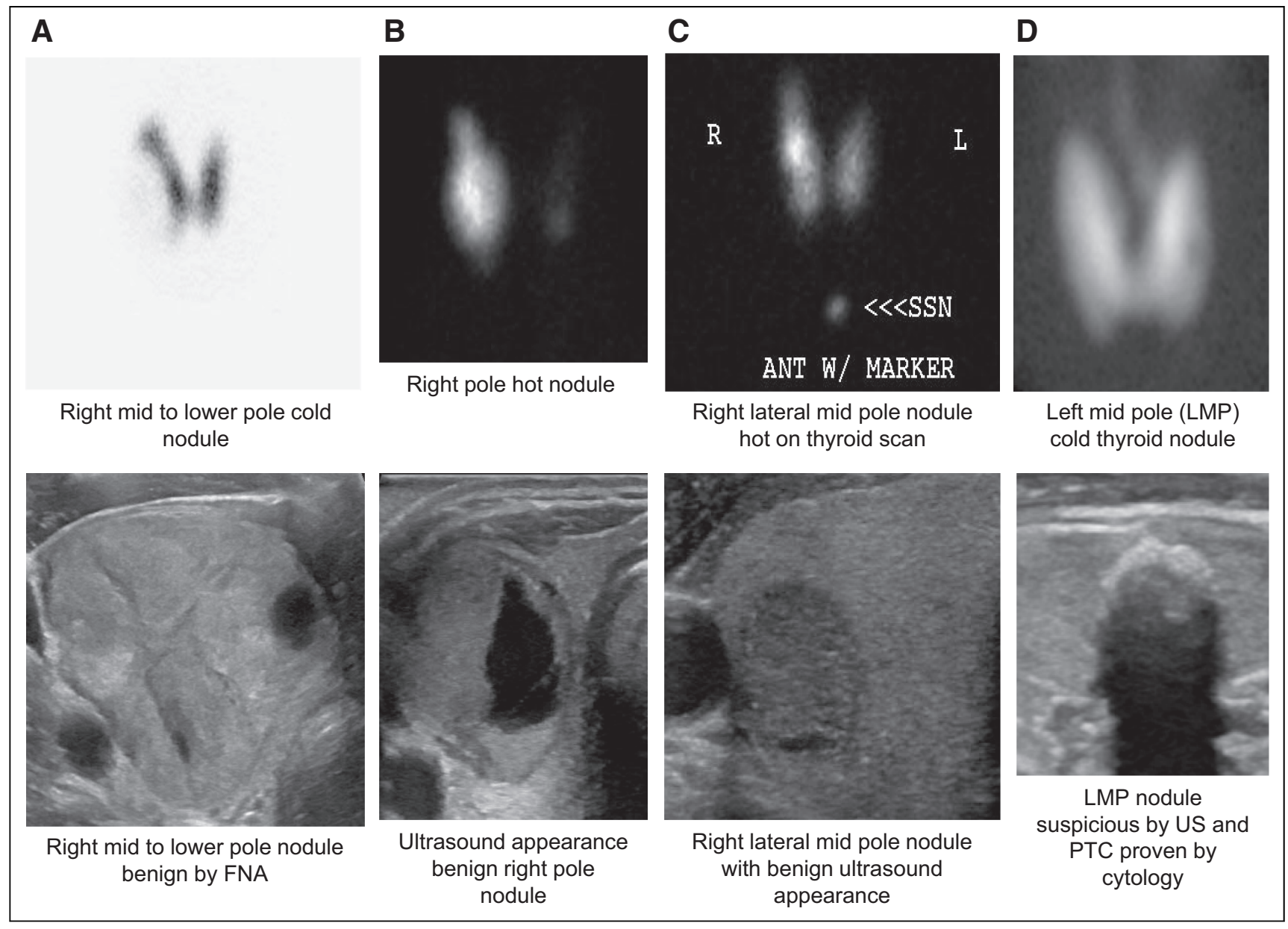

FIGURE 2. Scintigraphic thyroid scan findings (top) and matched US images (bottom). (A) Case 1. Euthyroid patient with cold right middle-lower TN with benign FNA cytology. (B) Case 2. Patient with thyrotoxicosis and autonomous right lobe TN with US evidence of some necrosis and otherwise benign features. (C) Case 3. Patient with mild TSH suppression and autonomous right (R) midlobe nodule in multinodular goiter with benign US appearance. ANT = anterior; L = left; SSN = supra-sternal notch; W/ = with. (D) Case 4. Patient with Graves disease and left midlobe cold nodule with concerning US appearance and cytology consistent with papillary thyroid cancer.

and include Afirma Genomic Sequencing Classifier with add-on Xpression Atlas, ThyroSeq 3.0, ThyGenX/ThyraMIR, and Rosetta GX Reveal (Veracyte, Sonic Healthcare USA Thyroseq Laboratory, Thyramir Interpace Diagnostics, and Rosetta Genomics, respectively). Mutations identified by these tests may aid in guiding management. For example, the presence of both BRAF V600E and TERT C228T in papillary thyroid cancer appears to be associated with poorer outcomes and so may have prognostic and management decision-making value (48). Conversely, the RAS mutation has been identified in benign nodules, follicular adenomas, the noninvasive follicular thyroid neoplasm with papillary-like nuclear features, papillary thyroid cancer (classic, follicular variant, and poorly differentiated), and anaplastic and medullary thyroid cancers (49). At present, the use of molecular marker results to guide therapeutic recommendations (i.e., extent of surgery or administration of radioactive iodine) has yet to be proven to improve outcomes and is not yet considered the standard of care; iu addition, the relatively high cost may be a limiting factor (50).

\section{Management}

An algorithm for the evaluation and management of TN is shown in Figure 3. Although no unanimous consensus exists, follow-up of cytologically benign, asymptomatic TN should be decided on the basis of US characteristics rather than an increase in volume (51). There is no complete agreement regarding the surveillance of subcentimeter TN. Highly suspicious subcentimeter TN warrant repeat US at 6-12 mo, whereas nodules for which the level of suspicion is very low, regardless of size, do not require follow-up imaging (13,52-54). The American College of Radiology recommends against scanning intervals of less than $1 \mathrm{y}$, except for biopsy-proven cancers under active surveillance (13). The chance of future cancer being found in a nodule with benign cytology is low and essentially becomes zero if another sampling yields benign cytology $(13,51,53-55)$. Current guidelines recommend repeat FNA when concerning US characteristics develop or an increase in volume of greater than or equal to $50 \%$ occurs, although the latter has been shown to have low specificity for malignancy (1,14,56-58). The American College of Radiology 2015 white paper provides recommendations for the follow-up of incidental $\mathrm{TN}$, including specific situations in which additional imaging is not necessary (59).

TN with nondiagnostic cytology should undergo repeat biopsy about 4-6 wk later. Alternatively, core needle biopsy can be considered, especially if concerning US features are present $(40,41)$. 


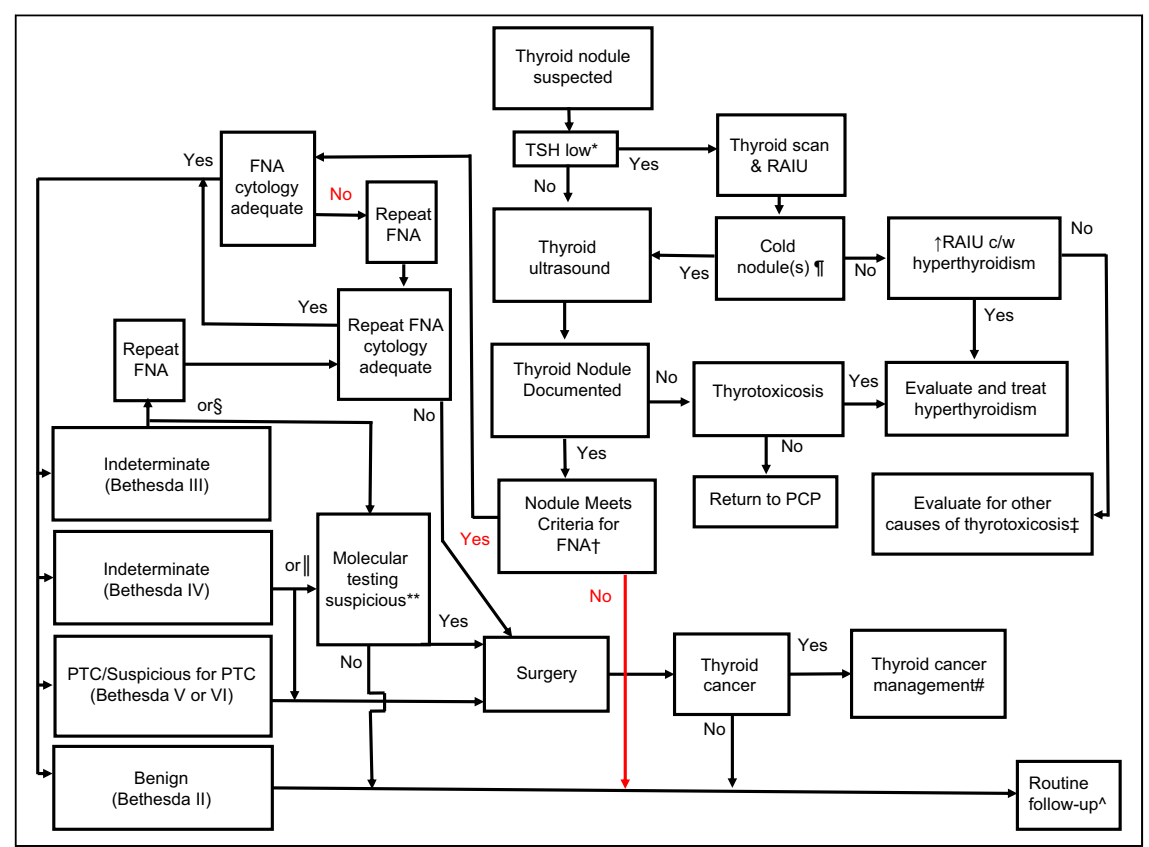

FIGURE 3. Algorithm for management of incidentally diagnosed TN. Bethesda $=$ Bethesda System for Reporting Thyroid Cytopathology, with associated roman numeral indicating cytology category; c/ $\mathrm{w}=$ consistent with; $\mathrm{PCP}=$ primary care physician; $\mathrm{RAIU}=$ radioactive iodine uptake; $\uparrow=$ increased. *Low TSH refers to TSH being below reference range, albeit there is some data on low reference range TSH levels being seen with autonomous nodules in populations with low dietary iodine intake. ${ }^{\dagger}$ Applying nodule size and US characteristics within accepted nodule grading system to estimate priority for pursuing FNAB. \#Thyroiditis or exogenous thyroid hormone. \$Indeterminate Bethesda III cytology; either wait 3-6 mo and reevaluate and repeat FNA or consider molecular testing now. Indeterminate Bethesda IV cytology; consider either molecular testing or proceeding to thyroid surgery. "For thyrotoxicosis with cold nodules, case should be run through algorithm and FNA should be used as appropriate. If benign, then nonsurgical forms of management can be reconsidered for thyrotoxicosis. "Thyroid cancer management may include active surveillance (particularly in papillary microcarcinomas of $<1 \mathrm{~cm}$ ), lobectomy, isthmusectomy, or total thyroidectomy plus TSH suppression therapy as appropriate. ${ }^{*}$ Molecular testing assay results need to be interpreted on basis of their individual parameters. In instances in which mutation such as BRAF is noted, thyroid cancer rate is effectively $100 \%$, whereas other mutations-such as RAS-have $60 \%-80 \%$ cancer risk and alterations in molecular expression are associated with various levels of risk for malignancy. $\wedge$ Very low risk nodules, regardless of size, do not require follow-up imaging.

TN below the threshold for FNAB but with "high-risk" features represent a challenging category and are subject to debate. Most guidelines recommend monitoring such high-risk subcentimeter TN with repeat US every 6-12 mo, unless additional risk factors are present. However, in clinical practice, many patients prefer not to forego further evaluation and insist on proceeding with FNAB. Sample adequacy represents an important issue with FNAB sampling of subcentimeter nodules and has been reported to be as low as $72.2 \%$ for 3 - to 6 -mm nodules, $84.9 \%$ for 7 - to 10 -mm nodules, and $63 \%$ in the presence of macrocalcifications $(60)$.

TSH suppression therapy to shrink TN in euthyroid individuals was in vogue for many years, and a metaanalysis published in 2005 found an $88 \%$ likelihood of achieving a reduction in nodule volume of greater than $50 \%$ compared with placebo or no treatment (61). However, the number needed to treat was $8: 1$, and TSH suppression therapy exposed patients to the risk of bone and cardiac complications from chronic iatrogenic hyperthyroidism. Current American Thyroid Association guidelines recommend against TSH suppression therapy as a standard therapy for euthyroid, iodine-sufficient populations (1).
Thyroid surgery for the management of benign $\mathrm{TN}$ may be considered when there is an association with compression symptoms, such as dysphagia, hoarseness, or choking sensation, and cosmetic concerns (62). Some researchers advocate that $\mathrm{TN}$ of greater than 3-4 cm should be considered for removal, although practical experience indicates that close follow-up of cytologically proven benign, asymptomatic nodules of this size is reasonable (63). $\mathrm{TN}$ found to harbor cancer and those with indeterminate cytology or molecular test results that indicate a significant cancer risk typically undergo resection. The extent of thyroid surgery is influenced by risk factors such as a history of childhood radiation exposure, histology (aggressive differentiated thyroid cancer variant and medullary or anaplastic thyroid cancer), the presence of bilateral nodules (particularly those larger than $1 \mathrm{~cm}$ on the contralateral side), or a family history of thyroid cancer. Active surveillance is an option with micropapillary thyroid cancers $(<1 \mathrm{~cm})$ that appear to be limited to the thyroid. It is preferable that such microcarcinomas be surrounded by a rim of normal thyroid tissue and that close follow-up with serial US imaging occurs (64-66).

Thyroid surgery is best performed by an experienced, high-volume thyroid surgeon so as to minimize surgical risks, such as transient or permanent postoperative hypoparathyroidism, hoarseness, and voice changes from recurrent laryngeal nerve damage (67). Patients should be counseled that hypothyroidism with a lifelong need for thyroid hormone therapy is a risk of thyroid surgery, occurring in approximately $15 \%-50 \%$ of patients after hemithyroidectomy; at higher rates in patients with smaller amounts of residual thyroid tissue, a higher preoperative TSH level, or underlying chronic lymphocytic thyroiditis; and, of course, in all patients after total thyroidectomy $(68,69)$.

\section{Nonsurgical Management}

Nonsurgical management of benign TN is a growing field and includes ethanol ablation for nodules; sclerotherapy for cysts; and thermal techniques, such as radiofrequency ablation, laser ablation, microwaves, and high-intensity focused US. Before any nonsurgical therapeutic option is used, TN should be proven benign, preferably by 2 FNAB samples, although 1 may suffice in very low-risk nodules (70). Anticoagulation therapy should be held before the procedure. Complications associated with thermal treatments are shown in Supplemental Table 3 and vary by patient selection and operator experience $(71,72)$. Ethanol ablation appears to be a more appropriate treatment option for sclerosis of pure thyroid cysts or treatment of autonomous TN (73-75). Intraprocedural 
perithyroidal ethanol leakage can cause patient discomfort and hoarseness from recurrent laryngeal nerve irritation (76).

Thermal ablation techniques appear to be more effective for the shrinkage of solid nodules, with radiofrequency ablation achieving a more significant volume reduction than laser ablation $(77,78)$. Microwaves were associated with a volume reduction rate of $74.6 \% \pm 10.9 \%$ at $12 \mathrm{mo}$; however, treatment failures appeared to be more prevalent when the treated nodule was at the edge of the thyroid and closer to vital neck structures (71). Microwaves were well tolerated, without major complications, except for transient periprocedural discomfort and voice changes (79). High-intensity focused US ablation also appears to be effective and resulted in a mean volume reduction of $48.7 \% \pm 24.3 \%(P<0.001)$ at 6 mo (Supplemental Table 3) (80). Such treatments are best performed at institutions with experience in these technologies.

\section{CONCLUSION}

$\mathrm{TN}$ are very common, and most of them are benign. The risk of malignancy can be assessed by means of US characteristics using available grading systems to assess malignancy risk and determine the indications for FNAB sampling. Scintigraphic imaging has a more limited role, being reserved for specific clinical scenarios. FNA cytology remains the gold standard in evaluating for the presence of malignancy, and molecular testing is a valuable tool for assessing cytologically indeterminate nodules. Surgical removal of cancerous or symptomatic nodules remains the first-line management option, although nonsurgical approaches have gained acceptance recently. TSH suppression therapy for shrinkage of benign nodules is not generally advised. Recommended follow-up of nodules should be individualized and based on clinical factors (Fig. 3). The follow-up interval between routine imaging assessments may be lengthened with evidence of continued nodule stability.

\section{DISCLOSURE}

No potential conflict of interest relevant to this article was reported.

\section{KEY POINTS}

QUESTION: Thyroid nodules are a common complaint in clinical practice and the vast majority are benign.

PERTINENT FINDINGS: The initial evaluation of a thyroid nodule should include assessment of thyroid function, clinical risk factors and neck imaging: thyroid ultrasound for assessing thyroid nodule morphology and scintigraphy are the first line study for assessing a hyperfunctioning nodule. Risk stratification systems have been developed using morphologic characteristics of thyroid nodules have been effective in reducing the number of unnecessary biopsies.

IMPLICATIONS FOR PATIENT CARE: While most malignant thyroid nodules are treated with surgery, active surveillance is an option in selected cases of micro-PTC. Nonsurgical approaches are gaining popularity as treatment options for malignant and asymptomatic benign thyroid nodules.

\section{REFERENCES}

1. Haugen BR, Alexander EK, Bible KC, et al. 2015 American Thyroid Association management guidelines for adult patients with thyroid nodules and differentiated thyroid cancer: the American Thyroid Association Guidelines Task Force on Thyroid Nodules and Differentiated Thyroid Cancer. Thyroid. 2016;26:1-133.
2. Durante C, Grani G, Lamartina L, Filetti S, Mandel SJ, Cooper DS. The diagnosis and management of thyroid nodules: a review. JAMA. 2018;319:914-924.

3. Guth S, Theune U, Aberle J, Galach A, Bamberger CM. Very high prevalence of thyroid nodules detected by high frequency $(13 \mathrm{MHz})$ ultrasound examination. Eur J Clin Invest. 2009;39:699-706.

4. Ahmed S, Horton KM, Jeffrey RB Jr, Sheth S, Fishman EK. Incidental thyroid nodules on chest CT: review of the literature and management suggestions. AJR. 2010;195:1066-1071.

5. Bahl M, Sosa JA, Nelson RC, Hoang JK. Imaging-detected incidental thyroid nodules that undergo surgery: a single-center experience over 1 year. AJNR. 2014;35:2176-2180.

6. Lim HK, Park ST, Ha H, Choi SY. Thyroid nodules detected by contrast-enhanced magnetic resonance angiography: prevalence and clinical significance. PLoS One. 2016;11:e0149811.

7. Steele SR, Martin MJ, Mullenix PS, Azarow KS, Andersen CA. The significance of incidental thyroid abnormalities identified during carotid duplex ultrasonography. Arch Surg. 2005;140:981-985.

8. Lim H, Devesa SS, Sosa JA, Check D, Kitahara CM. Trends in thyroid cancer incidence and mortality in the United States, 1974-2013. JAMA. 2017;317:1338-1348.

9. Tan GH, Gharib H. Thyroid incidentalomas: management approaches to nonpalpable nodules discovered incidentally on thyroid imaging. Ann Intern Med. 1997;126:226-231.

10. US Preventive Services Task Force; Bibbins-Domingo K, Grossman DC, et al. Screening for thyroid cancer: US Preventive Services Task Force Recommendation Statement. JAMA. 2017;317:1882-1887.

11. Brito JP, Gionfriddo MR, Al Nofal A, et al. The accuracy of thyroid nodule ultrasound to predict thyroid cancer: systematic review and meta-analysis. J Clin Endocrinol Metab. 2014;99:1253-1263.

12. Grant EG, Tessler FN, Hoang JK, et al. Thyroid ultrasound reporting lexicon: white paper of the ACR Thyroid Imaging, Reporting and Data System (TIRADS) Committee. J Am Coll Radiol. 2015;12:1272-1279.

13. Tessler FN, Middleton WD, Grant EG, et al. ACR Thyroid Imaging, Reporting and Data System (TI-RADS): white paper of the ACR TI-RADS Committee. $J$ Am Coll Radiol. 2017; 14:587-595.

14. Clark TJ, Pokharel S, Meier J, Wang C, Maximin S. Thyroid nodule doubling time is not a reliable indicator of benign or malignant nature. Ultrasound Q. 2016;32:132-135.

15. Shin JH, Baek JH, Chung J, et al. Ultrasonography diagnosis and imaging-based management of thyroid nodules: revised Korean Society of Thyroid Radiology Consensus Statement and Recommendations. Korean J Radiol. 2016;17:370-395.

16. Russ G, Bonnema SJ, Erdogan MF, Durante C, Ngu R, Leenhardt L. European Thyroid Association Guidelines for Ultrasound Malignancy Risk Stratification of Thyroid Nodules in Adults: the EU-TIRADS. Eur Thyroid J. 2017;6:225-237.

17. Gharib H, Papini E, Garber JR, et al. American Association of Clinical Endocrinologists, American College of Endocrinology, and Associazione Medici Endocrinologi Medical Guidelines for Clinical Practice for the Diagnosis and Management of Thyroid Nodules-2016 Update. Endocr Pract. 2016;22:622-639.

18. Yerubandi V, Chin BB, Sosa JA, Hoang JK. Incidental thyroid nodules at nonFDG PET nuclear medicine imaging: evaluation of prevalence and malignancy rate. AJR. 2016;206:420-425.

19. Abdel-Halim CN, Rosenberg T, Bjorndal K, et al. Risk of malignancy in FDGavid thyroid incidentalomas on PET/CT: a prospective study. World J Surg. 2019;43:2454-2458.

20. Choi JS, Choi Y, Kim EK, et al. A risk-adapted approach using US features and FNA results in the management of thyroid incidentalomas identified by ${ }^{18} \mathrm{~F}$-FDG PET. Ultraschall Med. 2014;35:51-58.

21. Soelberg KK, Bonnema SJ, Brix TH, Hegedus L. Risk of malignancy in thyroid incidentalomas detected by ${ }^{18} \mathrm{~F}$-fluorodeoxyglucose positron emission tomography: a systematic review. Thyroid. 2012;22:918-925.

22. Shie P, Cardarelli R, Sprawls K, Fulda KG, Taur A. Systematic review: prevalence of malignant incidental thyroid nodules identified on fluorine-18 fluorodeoxyglucose positron emission tomography. Nucl Med Commun. 2009;30:742-748.

23. Pattison DA, Bozin M, Gorelik A, Hofman MS, Hicks RJ, Skandarajah A. ${ }^{18} \mathrm{~F}$ FDG-avid thyroid incidentalomas: the importance of contextual interpretation. $J$ Nucl Med. 2018;59:749-755.

24. Hegedüs L, Bonnema SJ, Bennedbaek FN. Management of simple nodular goiter: current status and future perspectives. Endocr Rev. 2003;24:102-132.

25. Bennedbaek FN, Hegedus L. Management of the solitary thyroid nodule: results of a North American survey. J Clin Endocrinol Metab. 2000;85:2493-2498.

26. Bennedbaek FN, Perrild H, Hegedus L. Diagnosis and treatment of the solitary thyroid nodule: results of a European survey. Clin Endocrinol (Oxf). 1999;50:357-363.

27. Wahl RL. Thyroid radionuclide uptake and imaging studies. In: Braverman LE, Utiger RD, eds. Werner \& Ingbar's The Thyroid: A Fundamental and Clinical Text. Philadelphia, PA: Lippincott Williams \& WIlkins; 2000:257-278. 
28. Ashcraft MW, Van Herle AJ. Management of thyroid nodules. II: scanning techniques, thyroid suppressive therapy, and fine needle aspiration. Head Neck Surg. 1981;3:297-322.

29. Erjavec M, Movrin T, Auersperg M, Golouh R. Comparative accumulation of ${ }^{99 \mathrm{~m}} \mathrm{Tc}$ and ${ }^{131} \mathrm{I}$ in thyroid nodules: case report. J Nucl Med. 1977;18:346-347.

30. Langer JE, Agarwal R, Zhuang H, Huang SS, Mandel SJ. Correlation of findings from iodine 123 scan and ultrasonography in the recommendation for thyroid fineneedle aspiration biopsy. Endocr Pract. 2011;17:699-706.

31. Giovanella L, Avram AM, Iakovou I, et al. EANM practice guideline/SNMMI procedure standard for RAIU and thyroid scintigraphy. Eur J Nucl Med Mol Imaging. 2019;46:2514-2525.

32. Musholt TJ, Clerici T, Dralle H, et al. German Association of Endocrine Surgeons practice guidelines for the surgical treatment of benign thyroid disease. Langenbecks Arch Surg. 2011;396:639-649.

33. Hillenhinrichs H, Emrich D. Euthyroid goiter with and without functional autonomy in the euthyroid phase: a comparison [in German]. Nucl Med (Stuttg) 1998;37:95-100.

34. Kim DW, Rho MH, Kim KN. Ultrasound-guided fine-needle aspiration biopsy of thyroid nodules: is it necessary to use local anesthesia for the application of one needle puncture? Korean J Radiol. 2009;10:441-446.

35. Cao C, Jasim S, Cherian A, et al. Patient discomfort in relation to thyroid nodule fine-needle aspiration (FNA) performed with or without parenteral and/or topical anesthetic. Endocr Pract. 2020;26:1497-1504.

36. Cappelli C, Pirola I, Agosti B, et al. Complications after fine-needle aspiration cytology: a retrospective study of 7449 consecutive thyroid nodules. $\mathrm{Br}$ J Oral Maxillofac Surg. 2017;55:266-269.

37. Polyzos SA, Anastasilakis AD. Clinical complications following thyroid fineneedle biopsy: a systematic review. Clin Endocrinol (Oxf). 2009;71:157-165.

38. Shrestha M, Crothers BA, Burch HB. The impact of thyroid nodule size on the risk of malignancy and accuracy of fine-needle aspiration: a 10-year study from a single institution. Thyroid. 2012;22:1251-1256.

39. Koo DH, Song K, Kwon H, et al. Does tumor size influence the diagnostic accuracy of ultrasound-guided fine-needle aspiration cytology for thyroid nodules? Int J Endocrinol. 2016;2016:3803647.

40. Paja M, Del Cura JL, Zabala R, Korta I, Ugalde A, Lopez JI. Core-needle biopsy in thyroid nodules: performance, accuracy, and complications. Eur Radiol. 2019;29:4889-4896.

41. Wolinski K, Stangierski A, Ruchala M. Comparison of diagnostic yield of coreneedle and fine-needle aspiration biopsies of thyroid lesions: systematic review and meta-analysis. Eur Radiol. 2017;27:431-436.

42. Jung CK, Baek JH. Recent advances in core needle biopsy for thyroid nodules. Endocrinol Metab (Seoul). 2017;32:407-412.

43. Novoa E, Gurtler N, Arnoux A, Kraft M. Role of ultrasound-guided core-needle biopsy in the assessment of head and neck lesions: a meta-analysis and systematic review of the literature. Head Neck. 2012;34:1497-1503.

44. Yoon JH, Kim EK, Kwak JY, Moon HJ. Effectiveness and limitations of core needle biopsy in the diagnosis of thyroid nodules: review of current literature. J Pathol Transl Med. 2015;49:230-235.

45. Cibas ES, Ali SZ. The 2017 Bethesda System for Reporting Thyroid Cytopathology. Thyroid. 2017;27:1341-1346.

46. Bongiovanni M, Spitale A, Faquin WC, Mazzucchelli L, Baloch ZW. The Bethesda System for Reporting Thyroid Cytopathology: a meta-analysis. Acta Cytol. 2012;56:333-339.

47. Rao SN, Bernet V. Indeterminate thyroid nodules in the era of molecular genomics. Mol Genet Genomic Med. 2020;8:e1288.

48. Xing M, Liu R, Liu X, et al. BRAF V600E and TERT promoter mutations cooperatively identify the most aggressive papillary thyroid cancer with highest recurrence. J Clin Oncol. 2014;32:2718-2726.

49. Nikiforov YE, Seethala RR, Tallini G, et al. Nomenclature revision for encapsulated follicular variant of papillary thyroid carcinoma: a paradigm shift to reduce overtreatment of indolent tumors. JAMA Oncol. 2016;2:1023-1029.

50. Boelaert K. Molecular markers in diagnosing thyroid cancer. Endocrinologist (Bristol). 2019; Summer:1.

51. Kwak JY, Koo H, Youk JH, et al. Value of US correlation of a thyroid nodule with initially benign cytologic results. Radiology. 2010;254:292-300.

52. Grani G, Sponziello M, Pecce V, Ramundo V, Durante C. Contemporary thyroid nodule evaluation and management. J Clin Endocrinol Metab. 2020;105:2869-2883.

53. UAB Medicine News. Tessler heads international effort to standardize thyroid nodule guidelines. UAB Medicine website. https://www.uabmedicine.org/-/tesslerheads-international-effort-to-standardize-thyroid-nodule-guidelines. Accessed May 6, 2021.

54. Medici M, Liu X, Kwong N, et al. Long- versus short-interval follow-up of cytologically benign thyroid nodules: a prospective cohort study. BMC Med. 2016;14:11.
55. Durante C, Costante G, Lucisano G, et al. The natural history of benign thyroid nodules. JAMA. 2015;313:926-935.

56. Singh Ospina N, Maraka S, Espinosa DeYcaza A, et al. Diagnostic accuracy of thyroid nodule growth to predict malignancy in thyroid nodules with benign cytology: systematic review and meta-analysis. Clin Endocrinol (Oxf). 2016;85:122-131.

57. Kim M, Chung SR, Jeon MJ, et al. Determining whether tumor volume doubling time and growth rate can predict malignancy after delayed diagnostic surgery of follicular neoplasm. Thyroid. 2019;29:1418-1424.

58. Falch C, Axt S, Scuffi B, Koenigsrainer A, Kirschniak A, Muller S. Rapid thyroid nodule growth is not a marker for well-differentiated thyroid cancer. World J Surg Oncol. 2015;13:338.

59. Hoang JK, Langer JE, Middleton WD, et al. Managing incidental thyroid nodules detected on imaging: white paper of the ACR Incidental Thyroid Findings Committee. J Am Coll Radiol. 2015;12:143-150.

60. Li Y, Yu JH, Du PJ, et al. High-score US-suspicious subcentimeter thyroid nodules: what factors affect adequate sampling of US-guided fine-needle aspiration biopsy? Int J Endocrinol. 2020;2020:8464623.

61. Sdano MT, Falciglia M, Welge JA, Steward DL. Efficacy of thyroid hormone suppression for benign thyroid nodules: meta-analysis of randomized trials. Otolaryngol Head Neck Surg. 2005;133:391-396.

62. Chen AY, Bernet VJ, Carty SE, et al. American Thyroid Association statement on optimal surgical management of goiter. Thyroid. 2014;24:181-189.

63. Shin JJ, Caragacianu D, Randolph GW. Impact of thyroid nodule size on prevalence and post-test probability of malignancy: a systematic review. Laryngoscope. 2015; 125:263-272.

64. Ito Y, Uruno T, Nakano K, et al. An observation trial without surgical treatment in patients with papillary microcarcinoma of the thyroid. Thyroid. 2003;13:381-387.

65. Miyauchi A, Kudo T, Ito Y, et al. Estimation of the lifetime probability of disease progression of papillary microcarcinoma of the thyroid during active surveillance. Surgery. 2018;163:48-52.

66. Boucai L, Bernet V, Shaha A, Shindo ML, Stack BC, Tuttle RM. Surgical considerations for papillary thyroid microcarcinomas. J Surg Oncol. 2017;116:269-274.

67. Sosa JA, Bowman HM, Tielsch JM, Powe NR, Gordon TA, Udelsman R. The importance of surgeon experience for clinical and economic outcomes from thyroidectomy. Ann Surg. 1998;228:320-330.

68. Seiberling KA, Dutra JC, Bajaramovic S. Hypothyroidism following hemithyroidectomy for benign nontoxic thyroid disease. Ear Nose Throat J. 2007;86:295-299.

69. Johner A, Griffith OL, Walker B, et al. Detection and management of hypothyroidism following thyroid lobectomy: evaluation of a clinical algorithm. Ann Surg Oncol. 2011;18:2548-2554.

70. Papini E, Pacella CM, Solbiati LA, et al. Minimally-invasive treatments for benign thyroid nodules: a Delphi-based consensus statement from the Italian MinimallyInvasive Treatments of the Thyroid (MITT) Group. Int $J$ Hyperthermia. 2019;36:376-382.

71. Wang B, Han ZY, Yu J, et al. Factors related to recurrence of the benign nonfunctioning thyroid nodules after percutaneous microwave ablation. Int J Hyperthermia. 2017;33:459-464.

72. Kim C, Lee JH, Choi YJ, Kim WB, Sung TY, Baek JH. Complications encountered in ultrasonography-guided radiofrequency ablation of benign thyroid nodules and recurrent thyroid cancers. Eur Radiol. 2017;27:3128-3137.

73. Livraghi T, Paracchi A, Ferrari C, Reschini E, Macchi RM, Bonifacino A. Treatment of autonomous thyroid nodules with percutaneous ethanol injection: 4-year experience. Radiology. 1994;190:529-533.

74. Guglielmi R, Pacella CM, Bianchini A, et al. Percutaneous ethanol injection treatment in benign thyroid lesions: role and efficacy. Thyroid. 2004;14:125-131.

75. Di Lelio A, Rivolta M, Casati M, Capra M. Treatment of autonomous thyroid nodules: value of percutaneous ethanol injection. AJR. 1995;164:207-213.

76. Jang SW, Baek JH, Kim JK, et al. How to manage the patients with unsatisfactory results after ethanol ablation for thyroid nodules: role of radiofrequency ablation. Eur J Radiol. 2012;81:905-910.

77. Ha EJ, Baek JH, Kim KW, et al. Comparative efficacy of radiofrequency and laser ablation for the treatment of benign thyroid nodules: systematic review including traditional pooling and bayesian network meta-analysis. J Clin Endocrinol Metab. 2015;100:1903-1911.

78. Trimboli P, Castellana M, Sconfienza LM, et al. Efficacy of thermal ablation in benign non-functioning solid thyroid nodule: a systematic review and meta-analysis. Endocrine. 2020;67:35-43.

79. Yue W, Wang S, Wang B, et al. Ultrasound guided percutaneous microwave ablation of benign thyroid nodules: safety and imaging follow-up in 222 patients. Eur J Radiol. 2013;82:e11-e16.

80. Kovatcheva RD, Vlahov JD, Stoinov JI, Zaletel K. Benign solid thyroid nodules: US-guided high-intensity focused US ablation-initial clinical outcomes. Radiology. 2015;276:597-605. 